\title{
Electrospun Xanthan gum-Chitosan nanofibers as delivery carrier of hydrophobic bioactives
}

Shekarforoush, Elhamalsadat; Ajalloueian, Fatemeh; Zeng, Guanghong; Mendes, Ana Carina Loureiro; Chronakis, loannis S.

Published in:

Materials Letters

Link to article, DOI:

10.1016/j.matlet.2018.06.033

Publication date:

2018

Document Version

Peer reviewed version

Link back to DTU Orbit

Citation (APA):

Shekarforoush, E., Ajalloueian, F., Zeng, G., Mendes, A. C. L., \& Chronakis, I. S. (2018). Electrospun Xanthan gum-Chitosan nanofibers as delivery carrier of hydrophobic bioactives. Materials Letters, 228, 322-326.

https://doi.org/10.1016/j.matlet.2018.06.033

\section{General rights}

Copyright and moral rights for the publications made accessible in the public portal are retained by the authors and/or other copyright owners and it is a condition of accessing publications that users recognise and abide by the legal requirements associated with these rights.

- Users may download and print one copy of any publication from the public portal for the purpose of private study or research.

- You may not further distribute the material or use it for any profit-making activity or commercial gain

- You may freely distribute the URL identifying the publication in the public portal 


\section{Accepted Manuscript}

Electrospun Xanthan gum-Chitosan nanofibers as delivery carrier of hydrophobic bioactives

Elhamalsadat Shekarforoush, Fatemeh Ajalloueian, Guanghong Zeng, Ana C. Mendes, Ioannis S. Chronakis

PII: S0167-577X(18)30940-6

DOI: https://doi.org/10.1016/j.matlet.2018.06.033

Reference: MLBLUE 24473

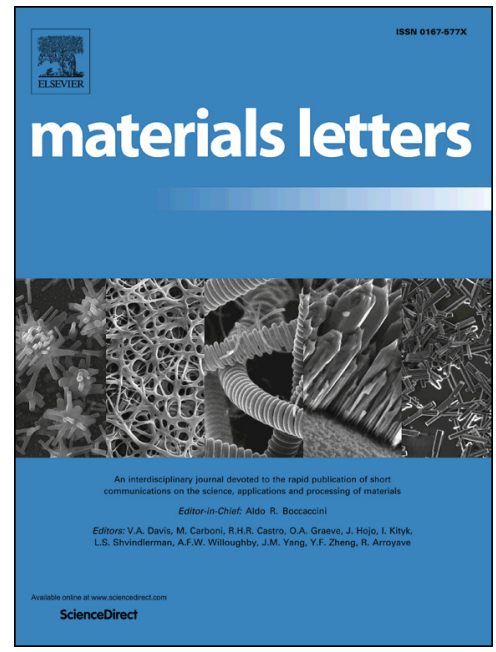

To appear in:

Materials Letters

Received Date:

27 March 2018

Revised Date:

25 May 2018

Accepted Date:

11 June 2018

Please cite this article as: E. Shekarforoush, F. Ajalloueian, G. Zeng, A.C. Mendes, I.S. Chronakis, Electrospun Xanthan gum-Chitosan nanofibers as delivery carrier of hydrophobic bioactives, Materials Letters (2018), doi: https://doi.org/10.1016/j.matlet.2018.06.033

This is a PDF file of an unedited manuscript that has been accepted for publication. As a service to our customers we are providing this early version of the manuscript. The manuscript will undergo copyediting, typesetting, and review of the resulting proof before it is published in its final form. Please note that during the production process errors may be discovered which could affect the content, and all legal disclaimers that apply to the journal pertain. 


\title{
Electrospun Xanthan gum-Chitosan nanofibers as delivery carrier of hydrophobic bioactives
}

\section{Elhamalsadat Shekarforoush, ${ }^{1}$ Fatemeh Ajalloueian, ${ }^{1}$ Guanghong Zeng, ${ }^{2}$ Ana C. Mendes, ${ }^{1}$ Ioannis S. Chronakis ${ }^{1}$}

${ }^{1}$ Nano-BioScience Research Group, DTU-Food, Technical University of Denmark, Kemitorvet B202, 2800 Kgs. Lyngby, Denmark

${ }^{2}$ Danish National Metrology Institute, Kogle Alle 5, DK-2970 Hoersholm, Denmark

\begin{abstract}
Viscoelastic gels of xanthan gum-chitosan $(\mathrm{X}-\mathrm{Ch})$ were electrospun to produce nanofibers, stable in aqueous media, for the encapsulation and release of curcumin (Cu). After 120h, the nanofibers released lower amount of curcumin $(\sim 20 \%)$ at $\mathrm{pH} 2.2$ comparatively to the release in neutral media ( $50 \%)$, suggesting that X-Ch nanofibers could be used as a carrier for the encapsulation of hydrophobic bioactive compounds with long-term $\mathrm{pH}$-stimulated release properties.
\end{abstract}

Keywords: Xanthan gum; Chitosan; Electrospinning; Drug delivery, Curcumin 


\section{Introduction}

The efficient delivery of hydrophobic bioactives, requires proper encapsulation to overcome concerns related with their low solubility and instability in aqueous body fluids, and limited bioavailability. Electrohydrodynamic (electrospinning and electrospray) methods have been widely studied due to their high encapsulation efficiency, low process temperature using a range broad food bioactive and shell ingredient [1]. Moreover, electrospun fibers comes along with high surface area, tunable diameter and surface functionality, which makes them very attractive for encapsulation and controlled bioactive release $[1,2]$.

Curcumin is a phenolic compound recognized by its pharmaceutical properties as an antioxidant, antimicrobial, anti-inflammatory agent and inhibitor of tumorigenesis and metastasis[3,4]. Due to its hydrophobicity and subsequent poor bioavailability, new delivery carriers have been investigated using electrospinning technology[5-7].

Chitosan (Ch) is a cationic polysaccharide consisting of $\mathrm{N}$-acetyl glucosamine and glucosamine known for its biocompatibility, biodegradability, and mucoadhesivity [8] and ability to enhance gastrointestinal drug absorption [9]. Xanthan (X) gum is an anionic polysaccharide known for its peculiar physico-chemical properties[10] and has been used as encapsulating matrix[11]. A recent study from our group found that X-Ch-Cu nanofibers incubated with Caco-2 cells, resulted in enhancement of the in vitro absorption of $\mathrm{Cu}$ across cell monolayers, with a 3-fold increase of $\mathrm{Cu}$ permeability, compared to free-curcumin. This work aims to investigate the X-Ch nanofiber development, morphological and encapsulation properties and evaluate its potential as a $\mathrm{Cu}$ release carrier in various $\mathrm{pH}$ media.

\section{Experimental}

\subsection{Materials}

All chemicals including xanthan gum (Mw about 2000 kDa [12], chitosan (Mw 28kD, degree of deacetylation (DD) of $89 \%$ and degree of polymerization (DP) of 175), curcumin and formic acid, were obtained from Sigma-Aldrich (Denmark).

\subsection{Preparation and characterization of electrospun solutions and fibers}

Xanthan $(0.75 \% \mathrm{w} / \mathrm{v})$ and chitosan $(3 \% \mathrm{w} / \mathrm{v})$ were dissolved in formic acid under vigorous stirring overnight at room temperature. Curcumin $(2 \% \mathrm{w} / \mathrm{v})$ was added to X-Ch solution, and stirred for 30 $\min . \mathrm{X}, \mathrm{Ch}$ and $\mathrm{X}$-Ch (with and without curcumin) rheological properties were determined[13]. X-Ch and X-Ch-Cu solutions were electrospun at $25 \mathrm{kV}$ (ES50P-10W, Gamma High Voltage Research, 
Inc., USA), feed rate of $0.01 \mathrm{~mL} / \mathrm{min}$ (syringe pump, New Era Pump Systems, USA) using a 21G needle (Proto Advantage, Canada). Fibers were collected on a stainless steel plate, placed $10 \mathrm{~cm}$ from the needle tip. Scanning electron microscopy (SEM) and fiber diameter distribution analyses (100 data points) followed the protocol described in[5]. Atomic force microscopy (AFM) was performed on Multimode 8 in PeakForce QNM mode. TAP150A probes with normial spring constant of $5 \mathrm{~N} / \mathrm{m}$ were used. To measure the adhesion force, deflection sensitivity calibration was performed on sapphire and spring constant (determined by thermal tuning). Adhesion map was formed by plotting the adhesion forces at each point, obtained from the retraction part of each force-distance curve. The encapsulation efficiency (EE) of the $\mathrm{Cu}$ within X-Ch nanofibers was determined by Cu fiber extraction using water and ethanol in a sonication bath [5].

\subsection{In vitro release studies}

X-Ch-Cu nanofibers (3.0 mg) were suspended in $2 \mathrm{~mL}$ of Tris buffered saline solution $(\mathrm{pH} 2.2,6.5$ and 7.6) at $37^{\circ} \mathrm{C}$ in a thermoshaker water bath. Supernatant aliquots $(100 \mu \mathrm{L})$ were withdrawn and replaced with the same volume of fresh media. The amount of $\mathrm{Cu}$ released was determined using a NanoDrop One UV-Vis Spectrophotometer (Thermo Fisher Scientific, Denmark) at the optical wavelength of $420 \mathrm{~nm}$. Triplicates were conducted for each sample.

\section{Results and Discussions}

Formation of a viscoelastic network with elastic modulus values ( $G$ ') higher than the viscous modulus (G") was observed for the X-Ch mixture in formic acid after 12.5 hours (Figure 1a). Individual xanthan and chitosan solutions exhibited G' higher than G'. The $\tan \delta$ value (tan $\delta=$ G"/G') for individual chitosan and xanthan solutions was 2,533 and 1,17 , respectively, denoting a liquid-like behaviour, whereas the tan $\delta$ of $X$-Ch mixture was 0.144 , confirming a gel-like behaviour as reported for other biopolymers gels[13].

Flow rheological studies (Figure 1 b) reveal that xanthan in formic acid has a shear thinning behaviour [13]. The chitosan solution shows nearly Newtonian behaviour at the shear rates of 0.1 to $100 \mathrm{~s}^{-1}$, and higher viscosity values than xanthan solution. However, a substantial viscosity increase was observed for $X$-Ch mixture. $X$ and $X$-Ch mixture followed a power-law thinning behaviour of $\eta=m \cdot \gamma^{n-1}$ where $\eta$ is the apparent viscosity, $\gamma$ the shear rate, and $m$ the flow index. The power law index values $(n)$ were in the range of $0.551-0.437$ for $\mathrm{X}$-Ch and $\mathrm{X}$-Ch-Cu, which are necessary to produce electrospun fibers[13]. The formation of a viscoelastic gel network, and an apparent viscosity increase of the $\mathrm{X}$-Ch mixture is due to the oppositely charged $\mathrm{X}$-Ch polyelectrolytes electrostatic interactions [14]. 
Figure 2 shows individual, uniform and randomly oriented X-Ch nanofibers with average diameters of $750 \mathrm{~nm}$. Note that both individual xanthan and chitosan solutions at the aforementioned concentrations could not be electrospun into fibers. The average diameter of electrospun xanthanchitosan nanofibers slightly increased to $910 \mathrm{~nm}$ with the addition of $2 \%$ curcumin, due to the increase of the solution viscosity (Figure 1b). The EE of Cu within X-Ch nanofibers was $69.4 \pm 4.1 \%$.

The X-Ch and X-Ch-Cu fibers' adhesive properties were quantified by Peakforce QNM, which measures adhesion force between the AFM tip (silicon) and nanofibers at each pixel (Figure 3). Adhesion forces from the top of the nanofibers are shown in the line profiles of X-Ch and X-Ch-Cu, with the average values of $10 \mathrm{nN}$, and $4 \mathrm{nN}$, respectively. X-Ch nanofibers displayed adhesive properties that decreased with the encapsulation of curcumin, due to the hydrophobic nature of this bioactive. The adhesive maps indicate that curcumin is incorporated homogeneously within X-ChCu nanofibers.

Figure 2 shows an $8-10 \%$ sustained release of curcumin from $\mathrm{X}$-Ch nanofibers over $12 \mathrm{~h}$ for all $\mathrm{pH}$ studied (2.2, 6.5 and 7.4) with no burst effect [6]. Beyond that, the release of curcumin at pH 2.2 was much lower than the other media, with no significant increase for up to $120 \mathrm{~h}$. On the other hand, the $\mathrm{Cu}$ release conducted in media at $\mathrm{pH} 7.4$ and 6.5 was increased beyond $12 \mathrm{~h}$ up to 45 and $50 \%$ respectively[6]. It is to note that $\mathrm{X}-\mathrm{Ch}$ and $\mathrm{X}-\mathrm{Ch}-\mathrm{Cu}$ nanofibers remained intact in all release media after $10-12 \mathrm{~h}$ at $37^{\circ} \mathrm{C}$ (data not shown). However, after $120 \mathrm{~h} \mathrm{X}$-Ch-Cu nanofibers slightly swelled in buffer at $\mathrm{pH} 6.5$ and 7.4 (about 3.5 times the initial fiber diameter), while at pH 2.2 the diameter increased about 1.5 times.

It is suggested, that the oppositely charged xanthan-chitosan mixture in formic acid is associated electrostatically [14]. When the electrospun nanofibers are immersed in the release media at different $\mathrm{pH}(\mathrm{s})$, the electrostatic equilibrium for both polyelectrolytes is expected to change. Consequently, at $\mathrm{pH}$ values below the pKA of chitosan (about 6.5), such at $\mathrm{pH} 2.2$, stronger interactions chitosan-xanthan are expected[15], resulting in denser nanofibers with lower swelling and lower diffusion of the bioactive. Korsmeyer-Peppas model[16], confirmed that the release of $\mathrm{Cu}$ at neutral $\mathrm{pH}$ followed non Fickian mechanism, an indicator of drug diffusion in the hydrated matrix and polymer relaxation (release exponents " $n$ " of $0.70(\mathrm{pH} 6.5)$ and $0.71(\mathrm{pH} 7.4))$. At $\mathrm{pH}$ 2.2 the release of $\mathrm{Cu}$ is described by the Higuchi mathematical model $\left(C=k t^{0.5}\right)$, with $k$ value of 2.13 .

\section{Conclusions}

Stable nanofibers were produced by the electrospinning of $\mathrm{X}$-Ch viscoelastic gels for the encapsulation and release of curcumin. The adhesion properties of the fibers were reduced with 
the addition of $\mathrm{Cu}$, due to its hydrophobic properties. The release of curcumin was controlled by the $\mathrm{pH}$ of the release media. At $\mathrm{pH} 2.2$ the nanofibers released lower amount of curcumin ( 20\%) compared to the release in neutral media ( 50\%) after $120 \mathrm{~h}$ due to the higher swelling of the matrix. The results indicated that electrospun X-Ch nanofibers could be used as a carrier for the encapsulation of hydrophobic bioactive compounds with high encapsulation efficiency, physical stability in aqueous media, and with long-term pH-stimulated release properties.

\section{Acknowledgments}

ES thanks DTU-Food for supporting her PhD stipend. GZ thanks the Danish Agency for Institutions and Educational Grants.

\section{References}

[1] A.C. Mendes, K. Stephansen, I.S. Chronakis, Electrospinning of food proteins and polysaccharides, Food Hydrocoll. 68 (2017) 53-68. doi:10.1016/j.foodhyd.2016.10.022.

[2] C. Jacobsen, P.J. Garcia-Moreno, A.C. Mendes, R. V Mateiu, I.S. Chronakis, Use of Electrospinning for Encapsulation of Sensitive Bioactive Compounds and Applications in Food, Annu. Rev. Food Sci. Technol. 9 (2018) 1-25.

[3] X.Z. Sun, G.R. Williams, X.X. Hou, L.M. Zhu, Electrospun curcumin-loaded fibers with potential biomedical applications, Carbohydr. Polym. 94 (2013) 147-153. doi:10.1016/j.carbpol.2012.12.064.

[4] D. PERRONE, F. ARDITO, G. GIANNATEMPO, M. DIOGUARDI, G. TROIANO, L. LO RUSSO, A. DE LILLO, L. LAINO, L. LO MUZIO, Biological and therapeutic activities, and anticancer properties of curcumin, Exp. Ther. Med. 10 (2015) 1615-1623. doi:10.3892/etm.2015.2749.

[5] E. Shekarforoush, A. Mendes, V. Baj, S. Beeren, I. Chronakis, Electrospun Phospholipid Fibers as Micro-Encapsulation and Antioxidant Matrices, Molecules. 22 (2017) 1708. doi:10.3390/molecules22101708.

[6] A.C. Mendes, C. Gorzelanny, N. Halter, S.W. Schneider, I.S. Chronakis, Hybrid electrospun chitosan-phospholipids nanofibers for transdermal drug delivery, Int. J. Pharm. 510 (2016) 48-56. doi:10.1016/j.ijpharm.2016.06.016.

[7] A. Blanco-Padilla, A. Lopez-Rubio, G. Loarca-Pina, L.G. Gomez-Mascaraque, S. Mendoza, Characterization, release and antioxidant activity of curcumin-loaded amaranth-pullulan electrospun fibers, LWT - Food Sci. Technol. 63 (2015) 1137-1144. doi:10.1016/j.lwt.2015.03.081.

[8] G. Borchard, H.L. Lueßen, A.G. de Boer, J.C. Verhoef, C.-M. Lehr, H.E. Junginger, The potential of mucoadhesive polymers in enhancing intestinal peptide drug absorption. III: Effects of chitosan-glutamate and carbomer on epithelial tight junctions in vitro, J. Control. Release. 39 (1996) 131-138. doi:10.1016/0168-3659(95)00146-8.

[9] A. Portero, C. Remuñán-López, H.M. Nielsen, The potential of chitosan in enhancing 
peptide and protein absorption across the TR146 cell culture model-an in vitro model of the buccal epithelium., Pharm. Res. 19 (2002) 169-74.

[10] B. Katzbauer, Properties and applications of xanthan gum, Polym. Degrad. Stab. 59 (1998) 81-84. doi:10.1016/S0141-3910(97)00180-8.

[11] A.C. Mendes, T. Strohmenger, F. Goycoolea, I.S. Chronakis, Electrostatic Self-Assembly of Polysaccharides into Nanofibers, Colloids Surfaces A Physicochem. Eng. Asp. 531 (2017) 182-188. doi:10.1016/j.colsurfa.2017.07.044.

[12] C.S. Wang, G. Natale, N. Virgilio, M.C. Heuzey, Synergistic gelation of gelatin B with xanthan gum, Food Hydrocoll. 60 (2016) 374-383. doi:10.1016/j.foodhyd.2016.03.043.

[13] E. Shekarforoush, A. Faralli, S. Ndoni, A.C. Mendes, I.S. Chronakis, Electrospinning of Xanthan Polysaccharide, Macromol. Mater. Eng. 201700067 (2017) 1700067. doi:10.1002/mame.201700067.

[14] M. Takahashi, M. lijima, K. Kimura, T. Hatakeyama, H. Hatakeyama, THERMAL AND VISCOELASTIC PROPERTIES OF XANTHAN GUM / CHITOSAN COMPLEXES IN AQUEOUS SOLUTIONS, 85 (2006) 669-674.

[15] H. Chen, Y. Song, N. Liu, H. Wan, N. Liao, G. Shu, Effect of complexation conditions on microcapsulation of B. bifidum BB01 in xanthan-chitosan polyelectrolyte complex gels, J. Chem. Pharm. Res. 6 (2014) 1355-1360. doi:10.1016/j.foodhyd.2007.12.011.

[16] R.W. Korsmeyer, R. Gurny, E. Doelker, P. Buri, N. a. Peppas, Mechanisms of solute release from porous hydrophilic polymers, Int. J. Pharm. 15 (1983) 25-35. doi:10.1016/03785173(83)90064-9. 
a

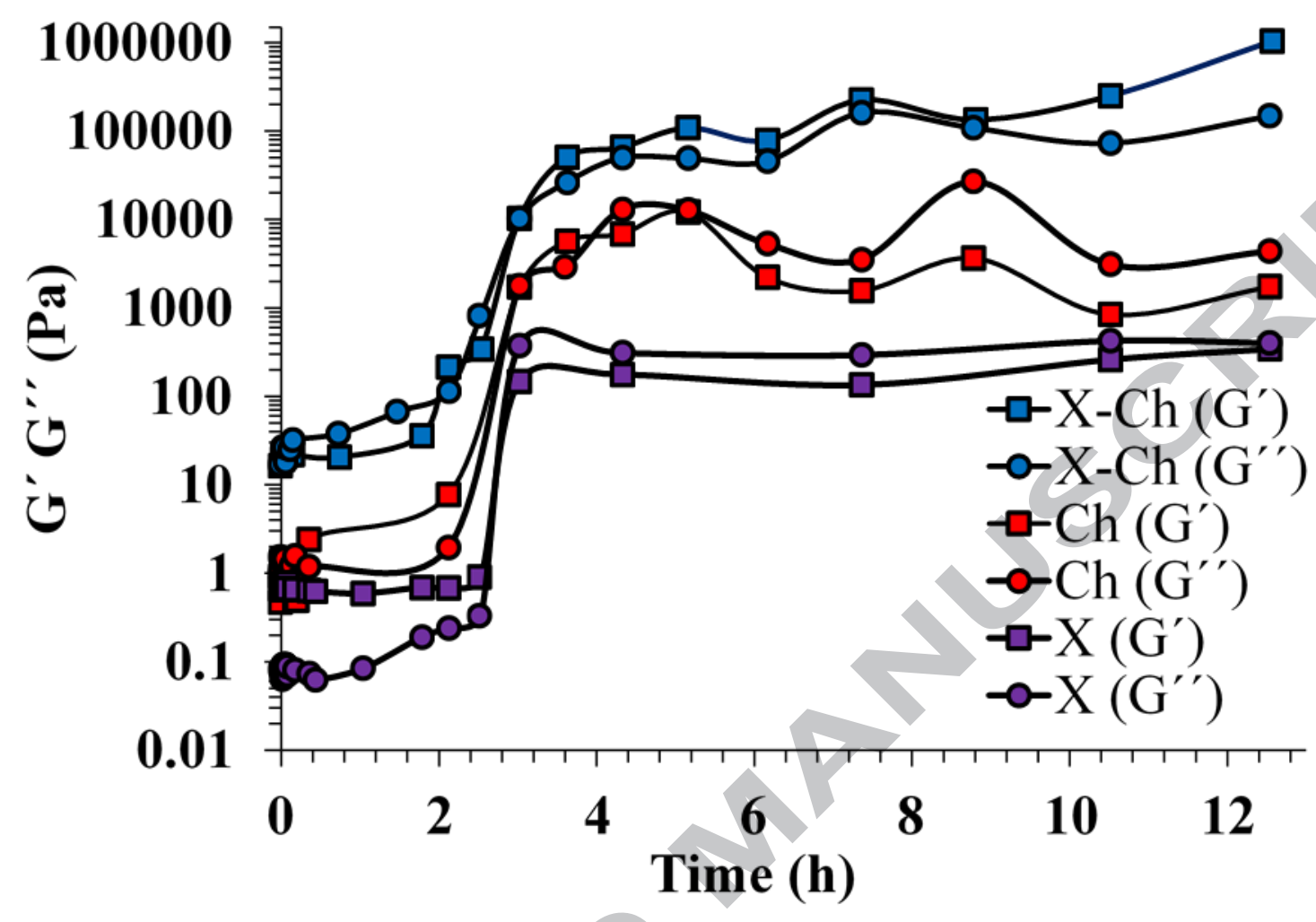

b

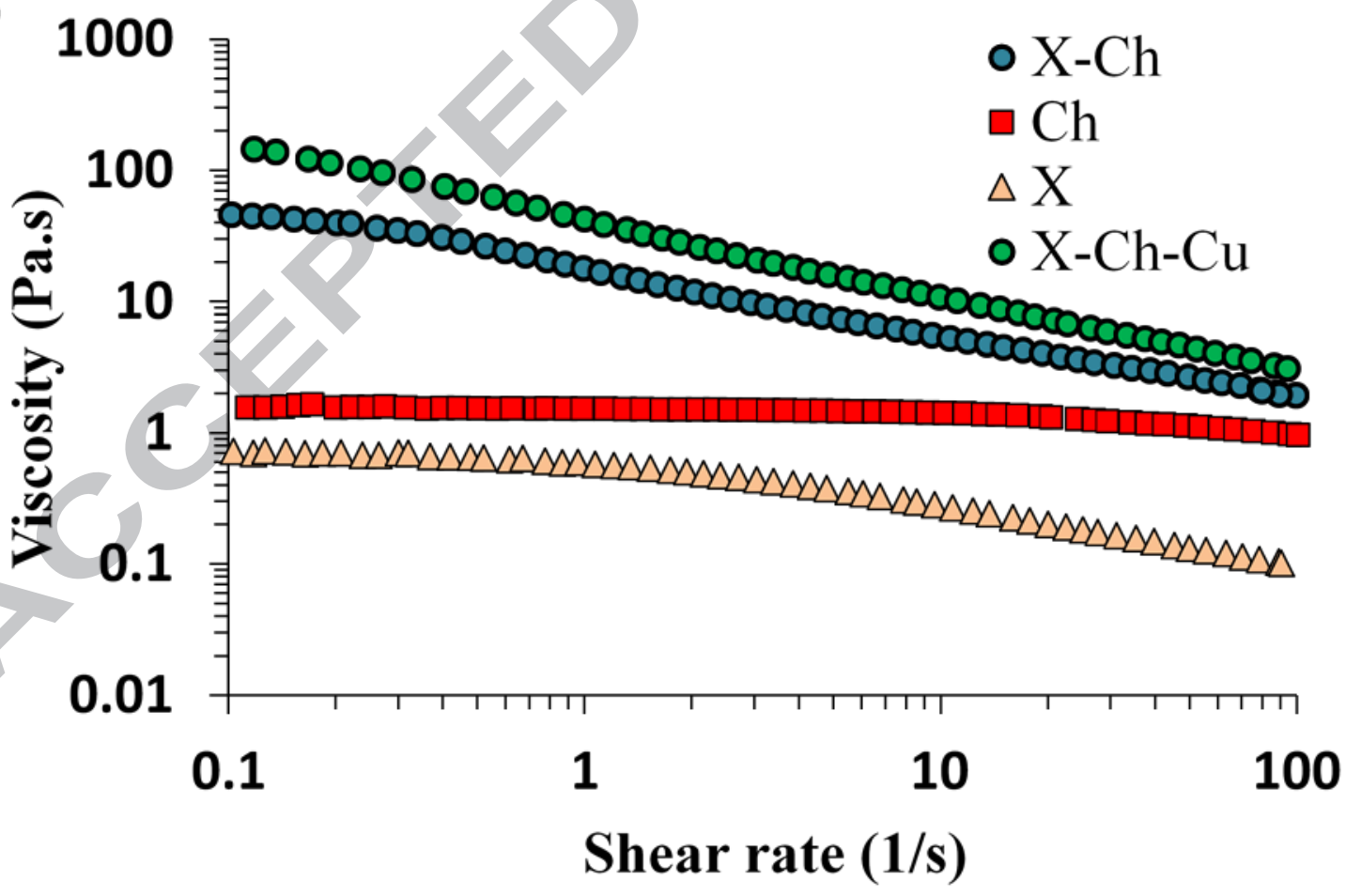

Figure 1. Viscoelastic properties over time (a) and flow curves (b) of $\mathrm{X}, \mathrm{Ch}, \mathrm{X}$-Ch and $\mathrm{X}-\mathrm{Xh}-\mathrm{Cu}$ solution. 


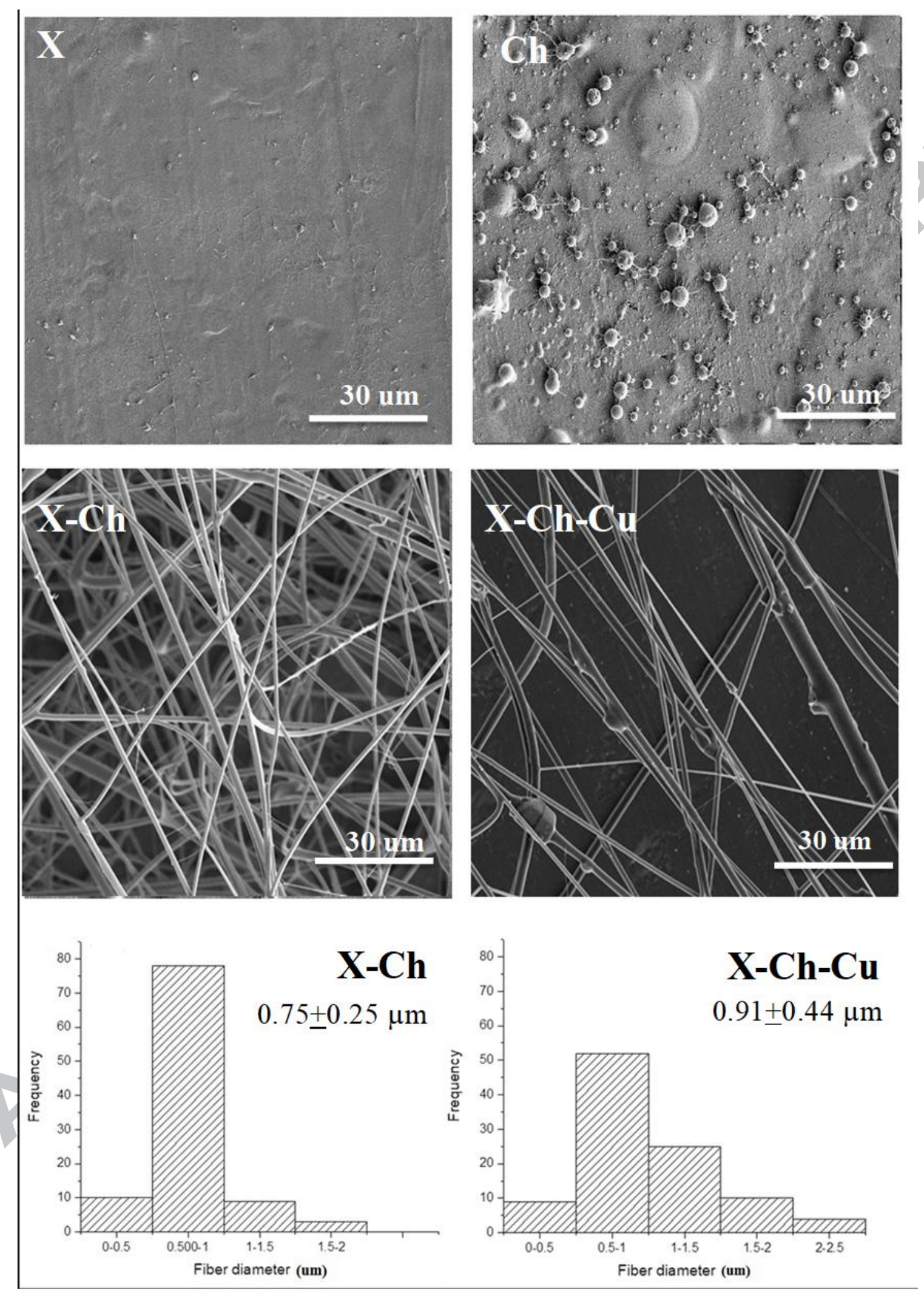

Figure 2. SEM images of electrospun X, Ch, X-Ch and X-Ch-Cu solutions and histograms displaying nanofibers diameter distribution. 


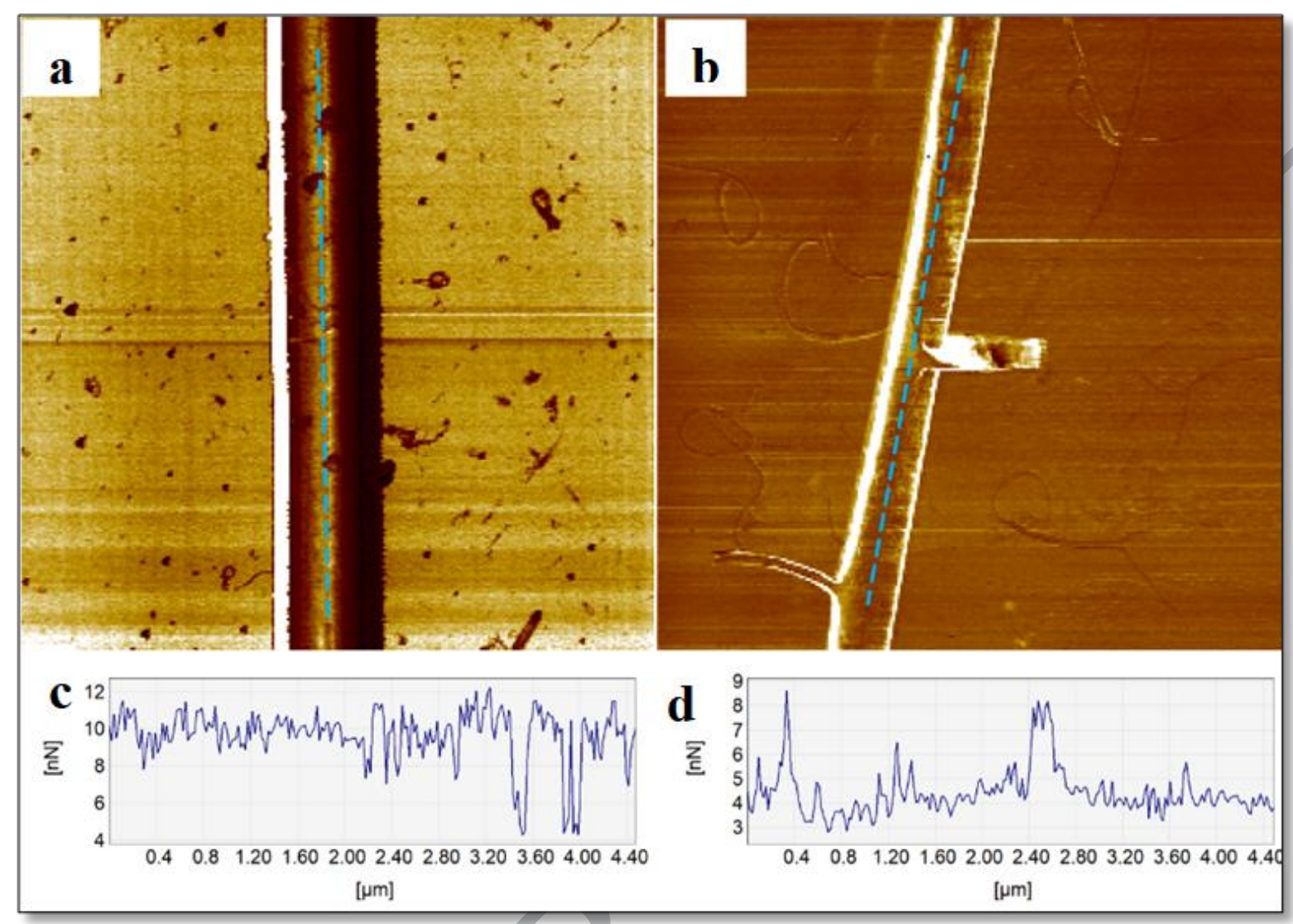

Figure 3. AFM adhesion maps of X-Ch (a), and X-Ch-Cu (b), and corresponding line profiles for X$\mathrm{Ch}(\mathrm{c})$ and X-Ch-Cu (d). 


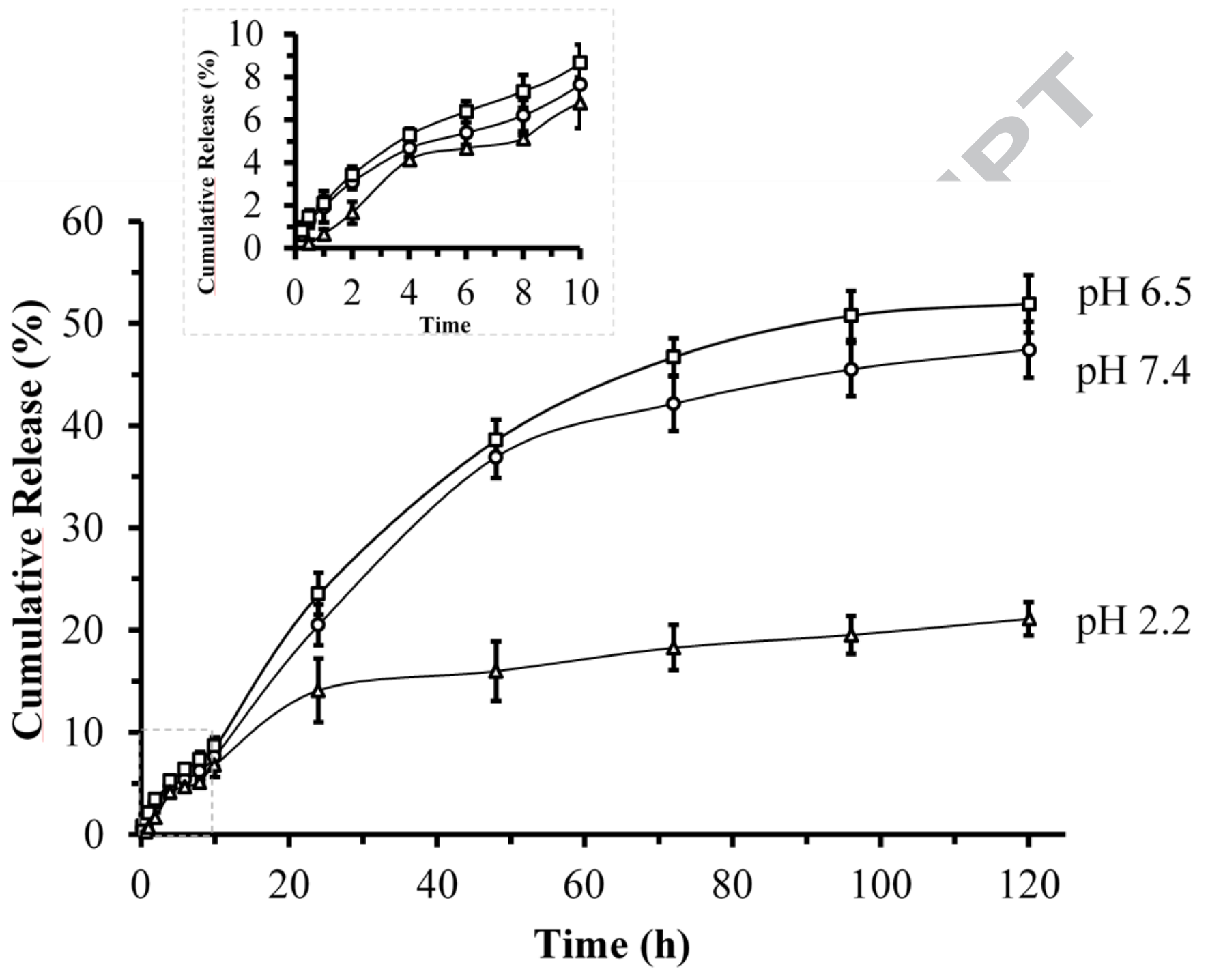

Figure 4. Release of Curcumin from X-Ch nanofibers in TRIS buffer solution, $37^{\circ} \mathrm{C}, \mathrm{pH} 2.2,6.5$, 7.4 . 


\section{Highlights}

- Electrospinning of viscoelastic gels of xanthan gum-chitosan

- Production of stable electrospun xanthan-chitosan nanofibers in aqueous media

- Production of a carrier for the controlled release of hydrophobic bioactive compounds with ability to enhance its bioavailability 